\title{
Kidney transplantation in childhood: mental health and quality of life of children and caregivers
}

\author{
Trond H. Diseth • Trine Tangeraas • Trude Reinfjell • \\ Anna Bjerre
}

Received: 14 December 2010 /Revised: 29 March 2011 /Accepted: 29 March 2011 / Published online: 26 April 2011

(C) The Author(s) 2011. This article is published with open access at Springerlink.com

\begin{abstract}
Our objective was to assess the mental health and health-related quality of life (HRQOL) in children and their parents after renal transplantation (TX) compared to healthy controls and children with acute lymphoblastic leukemia (ALL) and to identify possible health status variables associated with impaired mental health and HRQOL. Thirty-eight TX children with a median age of 13 (range 3-19) years were investigated. Mental health was assessed by the Pediatric Quality of Life Inventory (PedsQL) 4.0 Generic Core Scales and the Strength and Difficulties Questionnaire (SDQ-20). Each mother's own mental health and QOL were assessed by the General Health Questionnaire (GHQ-30) and the Quality of Life Scale (QOLS). Forty children with ALL [median age 11 (8.5-15.4) years] and 42 healthy children [median age $11(8.9-15)$ years] served as controls. Treadmill exercise results from 22 of the
\end{abstract}

T. H. Diseth

Department of Clinical Neurosciences for Children,

Women and Children's Division,

Oslo University Hospital and University of Oslo,

Oslo, Norway

T. Tangeraas $\cdot$ A. Bjerre

Department of Paediatric Medicine, Women and Children's

Division, Oslo University Hospital,

Oslo, Norway

\section{T. Reinfjell}

Department of Child and Adolescent Psychiatry,

St. Olavs University Hospital,

Trondheim, Norway

\section{T. H. Diseth $(\square)$}

Barne- og ungdomspsykiatrisk seksjon, Barneklinikken,

Oslo universitetssykehus HF, Rikshospitalet,

PO Box 4950 Nydalen, NO-0424 Oslo, Norway

e-mail: trond.diseth@oslo-universitetssykehus.no
38 patients were included in the analysis. TX children showed significantly higher levels of mental health problems and lower HRQOL at 2 to 16 years after transplantation compared to both control groups. Body mass index and maximal oxygen uptake $(n=22 / 38)$ were significant predictors of child mental health (SDQ) and child QOL (PedsQL), respectively. Based on these results, we suggest that rehabilitation after TX should include a focus on physical activity and QOL to reduce interconnected physical and psychological morbidity in kidney TX children.

Keywords Childhood kidney transplantation . Mental health · Quality of life - Body mass index · Cardiorespiratory fitness

\section{Introduction}

The Norwegian era of renal transplantation (TX) in children started in 1970 [1]. The TX option has resulted in a dramatic increase in the survival of children with end stage renal disease (ESRD) and has been the treatment of choice ever since its introduction. In Norway, $84 \%$ of pediatric renal transplants are provided from living related donors (LD), mostly parents (74\%). The pre-transplant dialysis time is short (median 3 months), and 50\% of transplantations are performed preemptively [1]; this provides good premises for graft survival and ensures a better quality of life (QOL) pre-transplant.

Over the decades, the introduction of more potent immunosuppressive medication and better pre- and posttransplant care have led to improvements in graft survival worldwide [2, 3]. In addition, increased surgical experience has made it possible to include infants $(<2$ years of age $)$ 
with ESRD in the TX program. The initial aim of TX has evolved from prolonging life to achieving long-term survival and enhancing the QOL to close to that of the age-matched general population.

However, both progressive chronic kidney disease (CKD) and the post-transplant period with mandatory immunosuppressive medication (IM) are associated with adverse physical and psychological consequences. This includes adverse effects on linear growth, weight gain, osteoporosis, reduced physical functioning, hypertension, reduced glucose tolerance and hyperlipidemia [4, 5]. Rejection of the graft followed by graft loss is a constant threat for both the child and caregiver. In the long run, children are at higher risk for cardiovascular disease, infections and malignancies, all of which contribute to increased long-term morbidity and mortality. Finally, the pre-, peri- and post-operative stress associated with renal transplantation per se and the fact that children during a transplantation are often isolated from their peer groups for long periods of time may increase the risk for mental and psychosocial disturbances, predisposing for a reduced QOL both for the child and the parents.

Previous research in children with advanced CKD until the need for renal replacement therapy has generally confirmed an increased risk of impaired mental health, psychosocial functioning and QOL [6-9]. However, most studies of psychosocial and QOL effects of CKD have included children with a wide variety of somatic status, and research has often failed to separate out the results by type of somatic status. Another challenge is that studies are performed at different stages of diagnosis or treatment and at various ages, with the patients having different developmental levels and psychological needs.

Earlier reports have stated good long-term QOL and psychosocial outcome after kidney TX during childhood [10-12]; however, these studies were conducted with adult patients and based on non-standardized questionnaires. There are only a few studies on health-related QOL (HRQOL) in CKD children and adolescents after kidney TX [8, 9, 13-22]. Most of these studies differ in their methodology and generally present conflicting results.

Studies on mental health and psychosocial functioning after kidney TX are even scarcer and diverge in their findings. Some indicate no differences between the transplant recipient and the healthy control [14, 23, 24], whereas others report an increased risk for maladaptive psychosocial sequels with emotional disturbances, such as anxiety, fear, depression, anger, withdrawal and symptoms of posttraumatic stress [15].

There is no controversy on the superiority of LD organ in terms of graft survival. However, little is known on the extent to which the LD graft benefit translates into a better QOL for the parent and child. We hypothesized that LD organ TX would have a more favorable QOL outcome for the child and parent relative to other severe pediatric chronic diseases. We also assumed that QOL issues are related to objective measures of physical functioning, as has been shown in studies of adult renal TX [25]. Therefore, the primary aim of this study was to explore aspects of mental health and HRQOL in children, adolescents and their caregivers after renal TX and compare these to those of healthy controls and children with another severe pediatric chronic disease, namely, acute lymphoblastic leukemia (ALL). The second aim was to investigate the potential associations between health status variables and mental health, psychosocial functioning and HRQOL.

\section{Patients and methods}

\section{Subjects}

All renal transplanted children in Norway undergo TX at the same University hospital and pay yearly visits, until transition to adult care at about 18 years of age. From this cohort, children and adolescents aged 2-19 years, transplanted between 1993 to 2006, were invited to participate in a cross-sectional study involving a 2-day comprehensive medical investigation program. Participants were enrolled from May 2008 to June 2009. Inclusion criteria were functioning graft for at least 1 year. Of the 50 patients asked to participate, 38 agreed $[76 \% ; 13(34 \%)$ girls, $25(66 \%)$ boys; median age 13 (range 3-19) years]. Parental information was obtained from 32 mothers [median age $40.5(25-51)$ years]. Average time since first transplantation was median $4.9(2-16)$ years. All patients except for one received prednisolone daily $(n=23)$ or every other day $(n=$ 14) [median $0.08(0.03-0.18) \mathrm{mg} / \mathrm{kg} /$ day]. There were no significant differences in sex, renal function, or proportion of LD recipients between the participants and nonparticipants, but non-participants $(n=12)$ were significantly older than the participants [median age 16.9 (6-20) years]. Data regarding the total patient cohort demographics, primary renal disease, pretransplant dialysis treatment, donor issues and number of transplants have been published previously [1].

A subgroup of the participants $(n=22 / 38)$ had previously been tested on the treadmill [26]. Of the 38 participants, children $<8$ years of age (too young for test requirements; $n=7)$ and patients with orthopedic limitations $(n=5)$ were excluded. Two adolescent girls eventually refused to be tested due to motivational problems and two adolescent boys ended the test before maximal effort was attained; these data were not included in the exercise test study.

The 38 transplanted children and adolescents were compared to 42 healthy controls [median age 11 (range 8.9-15.0)] 
recruited from two elementary schools and two junior high schools from both urban and rural areas in the middle part of Norway and to a group of 40 children with ALL [median age 11 (8.5-15.4)]. The control and comparison groups which serve as reference material for the patients in the present study were studied in a previous study and are extensively elaborated on in the papers of Reinfjell et al. [27, 28]. There were no significant differences between the three groups in terms of gender, age or socio-demographic characteristics, such as family composition, parental age and educational level, community, home and economy.

The baseline socio-demographic characteristics for the patients and the control and comparison groups are shown in Table 1.

\section{Measures}

\section{Anthropometrics and renal function}

Height was measured to the nearest $0.1 \mathrm{~cm}$ using a stadiometer. Weight was measured to the nearest $0.1 \mathrm{~kg}$ on a digital scale. Body mass index (BMI) was calculated as kilograms per square meter. Anthropometric data were converted to standard deviation scores (BMI $z$ score and height $z$ score) based on Cole's LMS method [29]. Overweight and obesity were defined according to BMI cut-off limits proposed by The International Task Force (isoBMI $>25$ and isoBMI $>30$, respectively) [30]. Glomerular filtration rate (mGFR) was measured using a single intravenous injection of iohexol with blood sampling after 3 $\mathrm{h}$ as previously reported [26].

\section{Exercise testing}

Cardiorespiratory fitness (CR Fitness) was defined as maximal oxygen uptake $\left(\mathrm{VO}_{2 \text { peak, }}\right.$ in $\left.\mathrm{ml} \mathrm{kg}{ }^{-0.67} \mathrm{~min}^{-1}\right)$ and was assessed with an incremental treadmill test until exhaustion. The treadmill test procedure and the evaluation criteria for a maximal test have been described in more detail in a previous report [26].

\section{Children's mental health, psychosocial functioning and $Q O L$}

The Strength and Difficulties Questionnaire (SDQ) was used to assess the mental and psychosocial health in children and adolescents [31]. The SDQ is a brief behavioral screening questionnaire consisting of 25 items in addition to a supplement on the impact of the difficulties for the child and family. Each item uses a three-point ordinal Likert format and can be answered with: "not true", "somewhat true" or "certainly true", rated 0-2 for negatively worded items and rated inversely $2-0$ for positively worded items. In this way, for all items, higher scores indicate more problematic attributes. There are five subscales: Emotional symptoms, Conduct problems, Hyperactivity, Peer problems and Prosocial behavior, with the first four adding up to the Total Difficulties Score. Subscores are generated for each subscale (range 0-10). A total difficulties score of $\geq 19$ defines symptom "caseness" according to Goodman (www.sdqinfo.com) and adjusted to Norwegian cut-offs [32]. As such, a symptom score $>90$ percentile predicts a substantially raised probability of being diagnosed with a psychiatric disorder, and a score of 16-18 is defined as "borderline", i.e., symptom score within percentile 80-90. The prosocial subscale measures the child's ability to act prosocially independent of the difficulties measured by the other subscale. The SDQ also includes a brief impact supplement where the respondent is asked whether he thinks he has a problem and, if so, inquires further about chronicity, overall distress, social impairment related to the family, friends, learning situation and leisure activities and, lastly, about the burden on the environment. The impact questions have four response categories which correspond with a point scale $0-0-1-2$. A total impact score of $\geq 2$ defines impact "caseness", i.e. having variable functioning with sporadic difficulties or symptoms in several but not all social areas, and a score of 1 is defined as borderline, i.e. having difficulty in a single area but generally functioning pretty well. There are similar versions for parents. The SDQ shows satisfactory reliability and validity $[31,33]$. Normative data based on a large representative Norwegian sample exist [32].

The Pediatric Quality of Life Inventory (PedsQL) 4.0 [34-36] was used to measure HRQOL in children and adolescents [37]. The 23-item PedsQL, version 4.0 Generic Core Scales, can be grouped into four domains of HRQOL: (1) Physical functioning (8 items), (2) Emotional functioning (5 items), (3) Social functioning (5 items) and (4) School functioning (5 items). The Generic Core Scales are comprised of a child self-report, with included ages of 5-7, 8-12 and 1318 years. Parent proxy-report includes ages $2-4,5-7,8-12$ and 13-18 and assesses parents' perceptions of their child's HRQOL. The items for the self-report and proxy-report are essentially identical, differing in developmentally appropriate language and first-or third-person tense.

The instructions ask how much of a problem each item has been during the past 1 month. $(0=$ never a problem; $1=$ almost never a problem; $2=$ sometimes a problem; $3=$ often a problem; $4=$ almost always a problem). Subjects are requested to rate how many problems they experienced during the past month with health (e.g. I hurt or ache), activities (e.g. It's hard for me to run) or feelings (e.g. I feel afraid or scared).

Items are reverse-scored and linearly transformed to a 0 100 scale $(0=100,1=75,2=50,3=25,4=0)$ so that higher 
Table 1 Socio-demographic characteristics of 38 children with kidney transplantation (TX) and their parents compared to children with acute lymphoblastic leukemia (ALL) and healthy controls. Treatment variables are reported for the children with TX and children with ALL
*Difference between TX and ALL/healthy respectively is significant at the 0.05 level (two-tailed)

TX, Transplantation (children with kidney transplantation); ALL, acute lymphoblastic leukemia; SD, standard deviation; GFR, glomerular filtration rate; GHQ, General Health Questionnaire; QOLS, Quality of Life Scale

\begin{tabular}{|c|c|c|c|}
\hline Socio-demographic characteristics & $\operatorname{TX}(n=38)$ & $\operatorname{ALL}(n=40)$ & Healthy $(n=42)$ \\
\hline \multicolumn{4}{|l|}{ Gender, $n(\%)$} \\
\hline Girl & $13(34)$ & $21(53)$ & $21(50)$ \\
\hline Boy & $25(66)$ & $19(47)$ & $21(50)$ \\
\hline \multicolumn{4}{|l|}{ Age at study (years) } \\
\hline Mean \pm SD & $12.2 \pm 4.0$ & $11.8 \pm 1.9$ & $11.8 \pm 1.9$ \\
\hline Median (range) & $13(3-19)$ & $11(8-15)$ & $12(8-15)$ \\
\hline \multicolumn{4}{|l|}{ Treatment } \\
\hline GFR $\left(\mathrm{ml} / \mathrm{min} / 1.73 \mathrm{~m}^{2}\right)$, median (range) & $51(22-95)$ & - & - \\
\hline Age at TX/diagnosis (ALL) in years, median (range) & $1.1(0-15)$ & $3.1(0-7)$ & - \\
\hline Years since TX/treatment (ALL), median (range) & $4.9(2-16)$ & $7.1(4-12)$ & - \\
\hline Parental characteristics & $n=32$ & & \\
\hline \multicolumn{4}{|l|}{ Family composition, $n(\%)$} \\
\hline Both parents & $25(78)$ & $31(77)$ & $29(70)$ \\
\hline Single parent & $7(22)$ & $9(23)$ & $13(30)$ \\
\hline \multicolumn{4}{|l|}{ Age in years, median (range) } \\
\hline Mother & $40.5(25-51)$ & $40.0(30-55)$ & $40.0(31-52)$ \\
\hline Father & $43.0(28-58)$ & $43.0(32-58)$ & $43.5(34-72)$ \\
\hline \multicolumn{4}{|l|}{ Education in years, median (range) } \\
\hline Mother & $13.0(8-18)$ & $14.0(10-19)$ & $13.0(9-19)$ \\
\hline Father & $12.0(9-17)$ & $14.0(10-20)$ & $13.0(10-19)$ \\
\hline \multicolumn{4}{|l|}{ Community, $n(\%)$} \\
\hline Urban & $16(50)$ & $15(37)$ & $18(43)$ \\
\hline Rural & $16(50)$ & $25(63)$ & $24(57)$ \\
\hline \multicolumn{4}{|l|}{ Home, $n(\%)$} \\
\hline Own house & $25(78)$ & $36(90)$ & $39(93)$ \\
\hline Own apartment & $3(9)$ & $3(8)$ & $3(7)$ \\
\hline Renting apartment & $4(13)$ & $1(2)$ & $0(0)$ \\
\hline \multicolumn{4}{|l|}{ Economy, $n(\%)$} \\
\hline Very satisfying & $14(44)$ & $27(67)$ & $21(50)$ \\
\hline Good & $16(50)$ & $8(20)$ & $21(50)$ \\
\hline Poor & $2(6)$ & $5(13)$ & $0(0)$ \\
\hline Mothers mental health/QOL & & $n=34$ & $\mathrm{n}=37$ \\
\hline GHQ case score (mean $\pm \mathrm{SD}$ ) & $2.1 \pm 4.8$ & $3.3 \pm 6.7$ & $1.2 \pm 3.3$ \\
\hline$n(\%)$ cases; cut-off: $5-30$ & $6(18.8)$ & $6(17.6)$ & $2(5.4)^{*}$ \\
\hline QOLS score $($ mean $\pm \mathrm{SD})$ & $90.4 \pm 10.0$ & - & - \\
\hline
\end{tabular}

scores indicate better HRQOL. Scale scores are computed as the sum of the items divided by the number of items answered (this accounts for missing data). In addition to the four subscales, a Total Summary Health score (23 items) can be computed. A Psychosocial Health Summary score (15 items) can be computed as the sum of the items divided by the number of items answered in the Emotional, Social, and School Functioning Subscales, and a Physical Health Summary score ( 8 items) is the same as the Physical Functioning subscale. The PedsQL 4.0 has achieved excellent reliability for the Total Scale score (0.89), and has been shown to differentiate between healthy children and children with chronic health conditions [38, 39]. PedsQL as a generic measure allows for the assessment of common dimensions among both healthy and chronically ill children as well as for comparisons across populations [40]. PedsQL has been shown to be an appropriate assessment tool for both healthy children, children with ALL [27] and children with CKD $[8,9,13]$. A Norwegian version of the PedsQL 4.0, concerning psychometric properties, is presented in more detail in an earlier work [41]. The PedsQL has shown satisfactory psychometric properties $[35,41]$.

\section{Maternal mental health and quality of life}

The General Health Questionnaire (GHQ) [42] is a widely used screening instrument for assessing the presence of distress, psychopathology and overall well-being in adults, 
showing acceptable and well-established reliability and validity. The GHQ includes both positive and negative questions, and the short version GHQ-30 contains 30 items covering symptoms considered to reflect psychological distress and well-being. Each question is answered on a four-point scale. The answers to each item may be treated both as a "Likert" score recommended for use in longitudinal studies when measuring change and have weights assigned to each position (0-1-2-3), with a possible scale of $0-90$, and as "Case" score, with weights $(0-0-1-1)$ and possible range of $0-30$. When using the GHQ-30 as a screening instrument for overall psychological distress, as in this study, the Case-scoring has proved to provide acceptable values for sensitivity and specificity [43]. A conventional cut-off was used; scores of $\geq 5$ were defined as "cases".

The Quality of Life Scale (QOLS) [44] is a questionnaire measuring an adult's overall satisfaction with life based on different life domains. It belongs to the category of global or overall QOL tools. The QOLS is a short questionnaire and contains additional information on areas not usually included in HRQOL measures, such as independence, material comfort, work satisfaction, recreation, etc. This scale has been widely used in health services research and has established psychometric properties and Norwegian norms [45]. The QOLS is a 16-item self-report and domainspecific instrument exploring factors such as physical and material well-being, personal development, relationships with others, participation in social, community and civic activities and recreation. The adults are asked to rate their present level of satisfaction with the above-mentioned factors on a seven-point scale. The scale is scored by adding up the items to obtain a total score with possible range 16-112. A higher score depicts a better quality of life.

\section{Statistics and ethics}

Continuous variables are presented as the mean \pm the standard deviation (SD) or if skewed as the median and range. Categorical variables are given as proportions and percentages. Differences between independent groups with regard to continuous variables were quantified with the two-sample $t$ test, or with the Mann-Whitney-Wilcoxon test in the case of severe skewness in the data. Categorical variables were compared between groups using the chisquared $\left(\chi^{2}\right)$ test or Fisher's exact test for small samples. The strength of associations between normally distributed continuous variables was measured using Pearson's correlation coefficient or Spearman's correlation coefficient when the variables had a skewed distribution.

Forward linear regression analysis was used to analyze possible explanatory variables as predictors of mental health and QOL [46]. Variables with $p<0.05$ from the univariate analysis were included in the multiple linear regression model. A careful check of the model assumptions, including an investigation of residual plots, did not reveal any violation of the assumptions.

All analyses were performed in SPSS ver. 16.0 (SPSS, Chicago, IL). We chose a 5\% statistical significance level.

Written informed consent was obtained from patients and/or their parents if less than 16 years of age prior to study start. The study protocol was approved by the National Committee for Research Ethics and carried out in accordance with the Declaration of Helsinki.

\section{Results}

Thirty-four children (89\%) received a kidney from a LD, with 27 (79\%) being donated from parents (13 mothers, 14 fathers), five from grandparents, one from a sibling and one from an aunt.

\section{Anthropometrics and exercise testing}

Thirteen patients $(34 \%)$ were overweight $(n=8)$ or obese $(n=5)$; the proportion of overweight patients among the treadmill participants was $36 \%(8 / 22)$. Eleven patients (29\%) were growth-retarded (height $z$ score $<-2$ ). In the treadmill participants, median $\mathrm{V}_{2 \text { peak }}$ was $66 \%$ (range $36-$ $97 \%$ ) of the expected values compared with the healthy controls $(n=196)$. Only three participants obtained $\mathrm{V}_{2} 0_{2 \text { peak }}$ within the expected range (i.e. $\mathrm{V} 0_{2 \text { peak }} z$ score $\geq-2$ ) (previously published data [26]).

Child mental health, psychosocial functioning and QOL

The SDQ and PedsQL for TX children, the group of ALL and the healthy controls are presented in Table 2.

Both the TX children and their mothers reported significantly higher SDQ scores than the healthy controls in terms of total difficulties, emotional problems and peer problems with more total difficulties caseness and impact score caseness. Relative to the healthy controls, the mothers reported even significantly higher SDQ scores regarding conduct problems and hyperactivity problems but lower prosocial behavior. Compared to the ALL group, the TX children and their mothers reported significantly higher SDQ scores regarding total difficulties, emotional problems and impact score, with more total difficulties in terms of caseness. The SDQ scores for the healthy controls are not significant different than the SDQ norms or reference values from the general Norwegian population [32].

Both the TX children and their mothers reported significantly lower HRQOL scores on all PedsQL items, with the exception of emotional functioning, than the 
Table 2 Health-related quality of life and Strength and Difficulties Questionnaire of 38 children with kidney transplantation (TX) compared to children with ALL and healthy controls
*Significant at the 0.05 level (two-tailed), **significant at the 0.001 level (two-tailed), $* * *$ significant at the .001 level (two-tailed) with respect to difference between TX and ALL/healthy patients/subjects

PedsQL, Pediatric Quality of Life Inventory; SDQ, Strength and Difficulties Questionnaire; HRQOL, health-related quality of life

Values are reported as the mean, with the SD in parenthesis unless stated otherwise

\begin{tabular}{|c|c|c|c|}
\hline Mental health and quality of life scales & $\mathrm{TX}(n=38)$ & $\operatorname{ALL}(n=40)$ & Healthy $(n=42)$ \\
\hline PedsQL child self-report & $n=30$ & & \\
\hline Total score & $69.10(17.98)$ & $81.70(12.56)^{* * *}$ & $88.98(7.57)^{* * *}$ \\
\hline Psychosocial health & $67.03(18.05)$ & $79.27(13.99)^{* *}$ & $87.22(9.20)^{* * *}$ \\
\hline Physical functioning & $74.89(17.01)$ & $86.25(12.13)^{* *}$ & $92.26(6.45)^{* * *}$ \\
\hline Emotional functioning & $69.48(15.81)$ & $75.13(18.69)$ & $83.21(12.68)^{* * *}$ \\
\hline Social functioning & $73.71(21.54)$ & $86.00(14.11)^{* *}$ & $92.50(7.67)^{* * *}$ \\
\hline School functioning & $63.10(17.75)$ & $76.63(16.38)^{* *}$ & $85.95(12.98)^{* * *}$ \\
\hline PedsQL mother proxy-report & $n=32$ & $n=36$ & $n=38$ \\
\hline Total score & $68.37(19.17)$ & $79.42(12.50)^{* *}$ & $89.62(10.26)^{* * *}$ \\
\hline Psychosocial health & $67.68(18.93)$ & $75.86(14.22)^{*}$ & $88.07(11.28)^{* * *}$ \\
\hline Physical functioning & $69.36(23.05)$ & $86.14(13.69)^{* * *}$ & $92.52(10.47)^{* * *}$ \\
\hline Emotional functioning & $70.00(21.36)$ & $70.28(15.63)$ & $85.00(13.46)^{* * *}$ \\
\hline Social functioning & $67.79(27.07)$ & $82.81(15.54)^{* *}$ & $93.16(9.89)^{* * *}$ \\
\hline School functioning & $62.90(23.16)$ & $74.44(19.88)^{*}$ & $86.05(14.57)^{* * *}$ \\
\hline SDQ child self-report & $n=26$ & $n=39$ & $n=41$ \\
\hline Total difficulties & $11.58(5.69)$ & $7.44(4.79)^{* *}$ & $5.71(4.28)^{* * *}$ \\
\hline No.(\%) caseness, $19-40$ & $2(8)$ & $1(3) * *$ & $0(0)^{* *}$ \\
\hline No.(\%) borderline, $16-18$ & $6(23)$ & $0(0)$ & $1(2)$ \\
\hline Emotional problems & $3.62(2.10)$ & $2.49(2.11)^{*}$ & $1.80(2.16)^{* * *}$ \\
\hline Conduct problems & $1.85(1.64)$ & $2.10(1.52)$ & $1.80(1.36)$ \\
\hline Hyperactivity problems & $3.58(2.18)$ & $3.05(1.86)$ & $3.27(2.28)$ \\
\hline Peer problems & $2.54(2.16)$ & $2.33(1.91)$ & $1.56(1.66)^{*}$ \\
\hline Prosocial behavior & $7.89(2.05)$ & $7.64(1.84)$ & $7.85(1.75)$ \\
\hline Impact score & $0.77(1.42)$ & $0.24(0.68)^{*}$ & $0.24(1.09)$ \\
\hline No.(\%) caseness, $2-10$ & $6(23)$ & $3(8)$ & $2(5)^{*}$ \\
\hline No.(\%) borderline, 1 & $1(4)$ & $2(5)$ & $0(0)$ \\
\hline SDQ mother proxy-report & $n=31$ & $n=36$ & $n=38$ \\
\hline Total difficulties & $10.74(6.30)$ & $7.61(5.15)^{*}$ & $4.18(3.57)^{* * *}$ \\
\hline No.(\%) caseness, $19-40$ & $4(13)$ & $2(6)$ & $0(0)^{* *}$ \\
\hline No.(\%) borderline, $16-18$ & $3(10)$ & $3(8)$ & $0(0)$ \\
\hline Emotional problems & $2.68(1.97)$ & $1.64(1.81)^{*}$ & $0.76(0.94)^{* * *}$ \\
\hline Conduct problems & $1.81(1.54)$ & $1.50(1.34)$ & $0.95(1.16)^{* *}$ \\
\hline Hyperactivity problems & $3.68(2.50)$ & $2.83(2.66)$ & $1.71(1.98)^{* *}$ \\
\hline Peer problems & $2.58(2.49)$ & $1.64(1.85)$ & $0.76(0.97)^{* * *}$ \\
\hline Prosocial behavior & $7.81(2.15)$ & $7.97(1.86)$ & $8.87(1.39)^{*}$ \\
\hline Impact score & $1.19(2.01)$ & $1.59(2.39)$ & $0.03(0.16)^{* * *}$ \\
\hline No.(\%) caseness, $2-10$ & $9(29)$ & $7(19)$ & $0(0)^{* * *}$ \\
\hline No.(\%) borderline, 1 & $0(0)$ & $0(0)$ & $1(3)$ \\
\hline
\end{tabular}

healthy controls and the ALL group. The SDQ and PedsQL scores were not associated with age, sex or years since the TX date. When the patients were classified into age groups according to the developmental perspective, i.e. 3-12 years and 13-18 years, we found no significant differences in the SDQ and PedsQL scores between the two groups. Furthermore, there were no significant differences between the scores of the children and the scores of their mothers on the SDQ or PedsQL.
Maternal mental health and QOL

The GHQ and QOLS for the mothers of TX children, the group of ALL and the healthy controls are presented in Table 1 . The mothers of TX children reported significantly more mental health problems (GHQ-case) than the mothers of healthy controls, but their scores were comparable with those of the ALL group. The QOLS scores in the control group are not significant different than QOLS norms or 
reference values from the general Norwegian population (mean 85.0, SD 12.3) [45]. When the patients were classified according to parental donorship $(n=27)$ or not, the mothers in the parental donor group reported significantly more mental health problems (GHQ) $(t=2.15, p=$ $0.043)$ and a tendency towards significant lower QOL ( $t=$ $-2.01, p=0.056)$ than the mothers in the non-parental donor group. All six GHQ cases were found in the parental donor group.

Associations between physical variables, maternal variables and children's mental, psychosocial and QOL outcome

There were significant correlations between the measures of physical status (height, BMI, CR Fitness), maternal variables (GHQ, QOLS) and the children's mental health/ psychosocial functioning (SDQ) and QOL (PedsQL) outcomes (Table 3). Renal function (GFR) did not correlate with any of these outcome variables. Strong associations $(r>0.60, p<0.001)$ were found between the PedsQL child self-report and PedsQL mother proxy-report in all PedsQL items, and between all SDQ child self-report and SDQ mother proxy-report.

Increased mental health problems (SDQ) were for some items significantly associated with physical outcomes - in most areas with increased BMI, but in some areas also with reduced CR Fitness and short stature-and with the mothers psychological distress (GHQ) and poorer QOL (QOLS).

Reduced PedsQL were for some items correlated with physical outcomes - in most areas with short stature and reduced CR Fitness, but in some areas also with increased BMI - and with the mothers psychological distress (GHQ) and poorer QOL (QOLS); see Table 3.

To investigate further the contribution of the independent physical and maternal variables in predicting mental (SDQ total score) and QOL (PedsQL total score) outcome, we used a multiple linear regression analysis. With SDQ total
Table 3 Significant associations between physical variables, parental variables and children's mental, psychosocial and quality of life outcomes
*Significant at the 0.05 level (two-tailed), $* *$ significant at the 0.001 level (two-tailed), $* * *$ significant at the .001 level (two-tailed)

CR Fitness, Cardiorespiratory fitness, was defined as maximal oxygen uptake $\left(\mathrm{VO}_{2 \text { peak }}\right)$

\begin{tabular}{|c|c|c|c|c|c|}
\hline Variables/outcomes & Height & Body mass index & CR Fitness & Mothers GHQ & Mothers QOL \\
\hline Body mass index & - & & & & \\
\hline CR fitness & $0.67 * * *$ & $-0.48^{*}$ & & & \\
\hline Mothers GHQ & - & $0.37 *$ & - & & \\
\hline Mothers QOLS & - & - & - & $-0.57 * *$ & \\
\hline \multicolumn{6}{|l|}{ PedsQL child } \\
\hline Total & $0.52 * *$ & - & $0.66^{* * *}$ & - & - \\
\hline Psychosocial & $0.56^{* * *}$ & - & $0.67 * * *$ & - & - \\
\hline Physical & - & - & $0.51^{*}$ & - & - \\
\hline Emotional & $0.44 *$ & - & $0.55^{*}$ & - & - \\
\hline Social & $0.49 * *$ & $-0.56^{* * *}$ & $0.50^{*}$ & - & - \\
\hline School & - & - & $0.70 * * *$ & - & - \\
\hline \multicolumn{6}{|l|}{ PedsQL mother } \\
\hline Total & $0.45^{* *}$ & $-0.44 *$ & $0.59 * *$ & - & $0.52 * *$ \\
\hline Psychosocial & $0.45^{* *}$ & $-0.50 * *$ & $0.59 * *$ & - & $0.52 * *$ \\
\hline Physical & $0.42 *$ & - & $0.51^{*}$ & - & $0.44^{*}$ \\
\hline Emotional & - & - & & - & $0.43^{*}$ \\
\hline Social & - & $-0.56 * * *$ & $0.63^{* *}$ & - & - \\
\hline School & $0.38 *$ & - & $0.49 *$ & $-0.44 *$ & $0.59 * * *$ \\
\hline \multicolumn{6}{|l|}{ SDQ child } \\
\hline Total & - & $0.48^{*}$ & - & - & $-0.46^{*}$ \\
\hline Emotional & $-0.42 *$ & - & $-0.53^{*}$ & - & $-0.49 * *$ \\
\hline Peer & - & $0.57 * *$ & - & - & - \\
\hline Prosocial & - & $-0.41^{*}$ & - & - & - \\
\hline Impact & - & $0.46^{*}$ & - & - & $-0.44 *$ \\
\hline \multicolumn{6}{|l|}{ SDQ mother } \\
\hline Total & $-0.36^{*}$ & $0.39 *$ & - & - & $-0.48^{*}$ \\
\hline Emotional & - & - & - & & $-0.43^{*}$ \\
\hline Peer & - & $0.35^{*}$ & - & $0.43 *$ & $-0.59 * * *$ \\
\hline Prosocial & - & $-0.46^{* *}$ & $0.47^{*}$ & - & - \\
\hline Impact & - & - & - & - & $-0.47 * *$ \\
\hline
\end{tabular}


score as the dependent variable, we entered age, gender, the physical correlates (height $z$ score, BMI $z$ score, $\mathrm{VO}_{2 \text { peak }}$ ) and maternal correlates (GHQ, QOLS) as explanatory variables (Table 4). The only significant predictor of mental health outcome was the BMI $z$ score, explaining $32 \%$ of the variance $(p=0.018)$.

Using the PedsQL total score as the dependent variable, we entered age, gender, the physical correlates (height, $\mathrm{BMI}, \mathrm{VO}_{2 \text { peak }}$ ) and the maternal correlates (GHQ, QOLS) as explanatory variables. $\mathrm{VO}_{2 \text { peak }}$ was the only significant predictor of QOL outcome $(n=22)$, explaining $42 \%$ of the variance $(p=0.005)$.

\section{Discussion}

The results of our study show that mental health, psychosocial adjustment and QOL of TX children are significantly impaired on both self-reports and proxyreports compared with those of healthy controls and in several areas, they are lower compared than those of the ALL group. The children's own perceived mental health and HRQOL was related to physical functioning and body composition, i.e. $\mathrm{VO}_{2 \text { peak }}$ and $\mathrm{BMI}$, respectively. The mothers' own mental health was significantly reduced compared to that of the controls, but comparable to that of ALL mothers. Our results demonstrate that both children and their parents carry a significant burden that lasts up to several years after kidney TX and therefore reflect the documented psychological and social at-risk status for children with chronic health conditions reported in the literature $[47,48]$.

Our findings are consistent with those of studies using PedsQL $[8,9,21,22]$ in which HRQOL was found to be impaired in kidney TX children and adolescents in comparison to healthy controls. The currently improving medical strategies in renal TX have entailed an increased awareness that the optimal care of children and adolescents with ESRD requires attention not only to medical management but also to the mental and psychosocial factors; understanding this may provide insights into non-adherence and non-compliance. Relatively few studies to date describe these important aspects in pediatric kidney transplant recipients and their parents, and those that do differ in their methodology and generally present conflicting results.
Additionally, parents of children with serious or chronic diseases may themselves be at risk for psychological problems to the extent that they can no longer be an effective source of protection and support for the child [49]. Thus, QOL should also include the long-term effects for the whole family as well.

A lack of concordance between children and caregivers has been reported in healthy [50] and chronically ill [51] children, suggesting information provided by proxy respondents is not equivalent to that reported by the patient. The child perspective often diverges from parental perceptions, particularly in the emotional and social domains. Previous research in CKD children and their parents has emphasized that the caregivers' perceptions of their child may underestimate the patient's own perception $[8,13]$. On the other hand, mothers with more psychological problems often rate their children as having more behavioral problems [7].

In opposite to others $[8,13,22]$, it is noteworthy that our TX children and their mothers rate the child's mental health and quality of life in accordance to each other; also in emotional and social domains. Our findings may suggest that parental donors identify more with the child due to organ share, in particular expressed by the mothers since they were the ones that accompanied their child to the investigations and thus were the responders of the questionnaires.

Both TX children and their mothers reported significantly lower HRQOL scores than children with ALL in all areas except emotional functioning and higher SDQ total difficulties, emotional problems and impact scores. The two patient groups are equivalent in gender, age and socio-economic background, such as family composition, parental age and educational level, community, home and economy, thus eliminating these factors as possible confounders. Although ALL and renal TX are completely different disease entities, our findings demonstrate a greater total burden on the family and child after renal TX. Our study further highlights the impact CKD may have on HRQOL when compared to another severe pediatric chronic disease [9].

The study on survivors of childhood ALL [27, 28] was conducted at a mean of 7 years after treatment-which is a time when the fear of relapse is less pronounced. Moreover, ALL in children starts abruptly, the treatment period for

Table 4 Forward multiple regression analyses predicting mental health outcome (SDQ) and quality of life outcome (PedsQL) in children and adolescents after transplantation

\begin{tabular}{llllrr}
\hline Model & Independent variable & B & $95 \%$ Confidence interval & Beta & $p$ value \\
\hline 1. SDQ & Body mass index & 1.79 & $(0.36,3.23)$ & 0.57 & 0.018 \\
2. PedsQL & VO $_{\text {2peak }}$ & 0.22 & $(0.08,0.36)$ & 0.65 & 0.005 \\
\hline
\end{tabular}


most ALL children lasts 2-2.5 years and the follow-up at the hospital ends 5-10 years after onset of disease. Renal TX is for the majority preceded with years with CKD, which affects both the child and its family. The frequent hospital visits and daily medications continue after TX and is a constant reminder of an everlasting chronic disease [7, 52].

At the same time, renal TX is a milestone for many families, even though the transition to normal life is difficult for both the parents and the child. The relief following regain of energy and appetite is hampered by strict surveillance of medication and blood samples several times a week in the early phase post TX. Parents may find it difficult to wean off habits of overprotection established before transplantation, reinforced by the wish to protect both their child and their own donated organ. In addition, the fear of rejection, non-compliance, risk of infections and poor graft function is a persistent threat. Moreover, approximately $50 \%$ of those transplanted in childhood will need a second kidney transplant before the age of 25 years [53].

Family functioning is one of the strongest contributors to psychosocial adjustment both in children with chronic health conditions and in healthy children [54]. It has been suggested that kidney donation and Tx have far-reaching implications for the whole family; each member will experience different changes that affect the family environment as a whole and the QOL of each person uniquely [55].

While some studies have evaluated the psychosocial functioning and QOL of CKD children and adolescents, there has been a lack of studies on parents' psychosocial functioning and HRQOL. In our study, mothers of TX children reported significantly more mental health problems than mothers of healthy controls, but their scores were comparable with those of the ALL mother comparison group. This is in accordance with one of few studies reporting that renal TX in children had a high impact on the parents, such as social isolation, emotional dysfunctioning, depression and posttraumatic stress symptoms [52]. Furthermore, in our study, the mothers of children with a parental donor had significantly more mental health problems than mothers of children receiving a kidney from nonparental donors; this is worrying, even though the numbers are low. This result is in contrast to previous research finding that the great majority of kidney donors and their partners experience no change or an improvement in their psychosocial health after donation [56, 57]. In a country like Norway, where LD in children has been a tradition since the start of the program, it is especially important to recognize the psychological trauma among the parental donors. Parents are subjected to a process of conflicting emotions. The donation of an organ is a life-saving procedure. At the same time, the parental donors must cope with the unspoken concern of own health after donating a kidney. However, a more comprehensive understanding of the psychological consequences of the donation process on the parents requires further study in which the fathers are also involved.

Most HRQOL studies on CKD children and adolescents have highlighted the psychosocial effects with less attention paid to its relation to physical effects [58]. In our study we revealed that the health status variables BMI, height and CR Fitness correlated and even predicted mental health problems, psychosocial dysfunction and poor QOL. It is now well established that short stature [59] is associated with a negative impact on overall QOL.

Several studies have reported on the low exercise capacity in CKD and ESRD children [19, 58, 60], but no studies have as yet explored the relation between an objective measure on CR Fitness $\left(\mathrm{VO}_{2 \text { peak }}\right)$ and HRQOL in renal TX children. Regular physical activity has been shown to have significant physical and mental health benefits [21, 61], including reduced anxiety, improved body image, self-esteem, mood and quality of life. CR Fitness $\left(\mathrm{VO}_{2 \text { peak }}\right)$ is considered to be the best measure of aerobic fitness and improves with exercise [62]. In a previous study, we showed that renal TX children and adolescents achieved only $66 \%$ of the expected CR Fitness compared to healthy children and that the majority reported being physical inactive [26]. Physical activity is a necessary and natural constituent of a child's life. However, the fatigue of ESRD and the overprotection from parents and the health system after TX may deprive these children from participating in sports and activities. Physical inactivity is in itself a risk factor for reduced self-esteem and obesity and, perhaps most importantly, may impair social interaction with peers and increase the risk for psychosocial dysfunction.

Both short stature and physical inactivity may foreshadow poor long-term psychosocial outcomes that have previously been observed and highlight the importance of early interventions to improve both linear growth and normalize height and to increase physical fitness in CKD children.

\section{Strength and limitations}

The strength of our study is that the TX children were followed-up at the same hospital and compared to a relevant control group and comparison group. However, a number of limitations should be noted. This study has a cross-sectional design, and we were therefore unable to control for premorbid functioning and for the small size of our group of children and their mothers. Cross-sectional designs cannot determine causal relations, implying that the results should be treated with some caution. 
As for most studies on children and adolescents with chronic diseases, including CKD, our study was based on selfreports and/or parental questionnaires. These general nonspecific questionnaires underestimate the overall prevalence of psychosocial dysfunctioning and psychopathology. More specific psychosocial problems and mild psychopathology appear to be difficult to elicit by questionnaires, indicating the need for including semistructured psychiatric or qualitative interviews within disease-specific areas. For future studies in this field, one has to encourage both longitudinal and qualitative studies to further explore QOL issues in renal TX children, including patients with other types of solid organ TX and utilizing transplant-specific HRQOL instruments in addition to generic HRQOL measures [40].

\section{Conclusion}

Mental health problems and psychosocial dysfunction can persist several years after diagnosis and treatment with renal TX, affecting the TX child's QOL and parental functioning. Optimal treatment and follow-up of TX children require close collaboration between pediatricians and psychosocial experts from birth to adulthood. Professional mental health guidance which includes developmental and family perspectives should be offered routinely to the TX patient and their parents.

With respect to the health status variables' (height, BMI, CR Fitness) impact on mental health and QOL, our study highlights the importance of early interventions to improve linear growth, reduce weight gain after TX and increase physical fitness. Our results suggest that emphasis during the follow-up period of entire family has also to be placed on physical rehabilitation programs and even measurements of exercise capacity, as compulsory therapy hand in hand with medical and psychosocial support. Health care providers should be the first to inform parents and the child about the importance of participating with peers in play and sport. A holistic, multifactorial approach towards the TX child and family is undoubtedly the best strategy to achieve both long-term graft survival and ensure a good QOL for both the child and parents.

Open Access This article is distributed under the terms of the Creative Commons Attribution Noncommercial License which permits any noncommercial use, distribution, and reproduction in any medium, provided the original author(s) and source are credited.

\section{References}

1. Tangeraas T, Bjerre A, Lien B, Kyte A, Monn E, Cvancarova M, Leivestad T, Reisaeter AV (2008) Long-term outcome of pediatric renal transplantation: the Norwegian experience in three eras 1970-2006. Pediatr Transplant 12:762-768
2. Rees L (2009) Long-term outcome after renal transplantation in childhood. Pediatr Nephrol 24:475-484

3. Shapiro R, Sarwal MM (2010) Pediatric kidney transplantation. Pediatr Clin N Am 57:393-400

4. Dharnidhark VR, Araya CE, Benfed MR (2007) Organ Toxicities. In: Fine R, Webber S, Olthoff K, Kelly D, Harmon W (eds) Pediatric solid organ transplantation, 2nd edn. Blackwell, Oxford, pp 124-136

5. Filler G, Huang SH (2010) Progress in pediatric kidney transplantation. Ther Drug Monit 32:250-252

6. Garralda ME, Jameson RA, Reynolds JM, Postlethwaite RJ (1988) Psychiatric adjustment in children with chronic renal failure. J Child Psychol Psychiatry 29:79-90

7. Madden SJ, Hastings RP, V'ant Hoff W (2002) Psychological adjustment in children with end stage renal disease: the impact of maternal stress and coping. Child Care Health Dev 28:323-330

8. McKenna AM, Keating LE, Vigneux A, Stevens S, Williams A, Geary DF (2006) Quality of life in children with chronic kidney disease-patient and caregiver assessments. Nephrol Dial Transplant 21:1899-1905

9. Goldstein SL, Graham N, Burwinkle T, Warady B, Farrah R, Varni JW (2006) Health-related quality of life in pediatric patients with ESRD. Pediatr Nephrol 21:846-850

10. Morel P, Almond PS, Matas AJ, Gillingham KJ, Chau C, Brown A, Kashtan CE, Mauer SM, Chavers B, Nevins TE, Dunn DL, Sutherland DER, Payne WD, Najarian J (1991) Long-term quality of life after kidney transplantation in childhood. Transplantation 52:47-53

11. Krmar RT, Eymann A, Ramirez JA, Ferraris JR (1997) Quality of life after kidney transplantation in children. Transplantation 64:540-541

12. Kärrfelt HM, Berg UB (2008) Long-term psychosocial outcome after renal transplantation during childhood. Pediatr Transplant 12:557-562

13. Goldstein SL, Graham N, Warady BA, Seikaly M, McDonald R, Burwinkle TM, Limbers CA, Varni JW (2008) Measuring healthrelated quality of life in children with ESRD: performance of the generic and ESRD-specific instrument of the Pediatric Quality of Life Inventory (PedsQL). Am J Kidney Dis 51:285-297

14. Qvist E, Närhi V, Apajasalo M, Rönnholm K, Jalanko H, Almqvist F, Holmberg C (2004) Psychosocial adjustment and quality of life after renal transplantation in early childhood. Pediatr Transplant 8:120-125

15. Falger J, Landolt MA, Latal B, Rüth EM, Neuhaus TJ, Laube GF (2008) Outcome after renal transplantation. Part II: quality of life and psychosocial adjustment. Pediatr Nephrol 23:1347-1354

16. Manificat S, Dazord A, Cochat P, Morin D, Plainguet F, Debray D (2003) Quality of life of children and adolescents after kidney or liver transplantation: child, parents and caregiver's point of view. Pediatr Transplant 7:228-235

17. Hasegawa A, Oshima S, Takahashi K, Uchida K, Ito K, Sonoda T (2005) Improvement of quality of life in tacrolimus-based pediatric renal transplant recipients and their caregivers, including donors. Transplant Proc 37:1771-1773

18. Gerson A, Hwang W, Fiorenza J, Barth K, Kaskel F, Weiss L, Zelikovsky N, Fivush B, Furth S (2004) Anemia and healthrelated quality of life in adolescents with chronic kidney disease. Am J Kidney Dis 44:1017-1023

19. Eijsermans RM, Creemers DG, Helders PJ, Schröder CH (2004) Motor performance, exercise tolerance, and health-related quality of life in children on dialysis. Pediatr Nephrol 19:1262-1266

20. Sundaram SS, Landgraf JM, Neighbors K, Cohn RA, Alonso EM (2007) Adolescent health-related quality of life following liver and kidney transplantation. Am J Transplant 7:982-989

21. Hamiwka LA, Cantell M, Crawford S, Clark CG (2009) Physical activity and health related quality of life in children following kidney transplantation. Pediatr Transplant 13:861-867 
22. Anthony SJ, Hebert D, Todd L, Korus M, Langlois V, Pool R, Robinson LA, Williams A, Pollock-BarZiv SM (2010) Child and parental perspectives of multidimensional quality of life outcomes after kidney transplantation. Pediatr Transplant $14: 249-256$

23. Soliday E, Kool E, Lande MB (2000) Psychosocial adjustment in children with kidney disease. J Pediatr Psychol 25:93-103

24. Kärrfelt HM, Lindblad FI, Crafoord J, Berg UB (2003) Renal transplantation: long-term adaptation and the children's own reflections. Pediatr Transplant 7:69-75

25. Painter PL, Hector L, Ray K, Lynes L, Dibble S, Paul SM, Tomlanovich SL, Ascher NL (2002) A randomized trial of exercise training after renal transplantation. Transplantation 74:42-48

26. Tangeraas T, Midtvedt K, Fredriksen PM, Cvancarova M, Mørkrid L, Bjerre A (2010) Cardiorespiratory fitness is a marker of cardiovascular health in renal transplanted children. Pediatr Nephrol 25:2343-2350

27. Reinfjell T, Lofstad GE, Veenstra M, Vikan A, Diseth TH (2007) Health-related quality of life and intellectual functioning in children in remission from acute lymphoblastic leukaemia. Acta Paediatr 96:1280-1285

28. Reinfjell T, Lofstad GE, Nordahl HM, Vikan A, Diseth TH (2009) Children in remission from acute lymphoblastic leukaemia: mental health, psychosocial adjustment and parental functioning. Eur J Cancer Care 18:364-370

29. Cole TJ, Freeman JV, Preece MA (1995) Body mass index reference curves for the UK, 1990. Arch Dis Child 73:25-29

30. Cole TJ, Bellizzi MC, Flegal KM, Dietz WH (2000) Establishing a standard definition for child overweight and obesity worldwide: international survey. Br Med J 320:1240-1243

31. Goodman R (1999) The extended version of the Strengths and Difficulties Questionnaire as a guide to child psychiatric caseness and consequent burden. J Child Psychol Psychiatr 40:791-799

32. Van Roy B, Grøholt B, Heyerdahl S, Clench-Aas J (2006) Selfreported strengths and difficulties in a large Norwegian population 10-19 years: age and gender specific results of the extended SDQquestionnaire. Eur Child Adolesc Psychiatr 15:189-198

33. Obel C, Heiervang E, Rodriguez A, Heyerdahl S, Smedje H, Sourander A, Guethmundsson OO, Clench-Aas J, Christensen E, Heian F, Mathiesen KS, Magnússon P, Njarethvík U, Koskelainen M, Rønning JA, Stormark KM, Olsen J (2004) The Strengths and Difficulties Questionnaire in the Nordic countries. Eur Child Adolesc Psychiatr 13[Suppl 2]:II32-II39

34. Varni JW, Seid M, Rode CA (1999) The PedsQL: Measurement model for the Pediatric Quality of Life Inventory. Med Care $37: 126-139$

35. Varni JW, Seid M, Kurtin PS (2001) PedsQL 4.0: Reliability and validity of the Pediatric Quality of Life Inventory version 4.0 generic core scales in healthy and patient populations. Med Care 39:800-812

36. Varni JW (1998) PedsQL TM Translation methodology. Available at: http://www.pedsql.org

37. Eiser C, Morse R (2001) The measurement and quality of life in children: past and future perspectives. Dev Behav Pediatr 22 (4):248-256

38. Varni JW, Burwinkle TM, Seid M (2006) The PedsQL 4.0 as a school population health measure: feasibility, reliability, and validity. Qual Life Res 15:203-215

39. Varni JW, Burwinkle TM, Seid M, Skarr D (2003) The PedsQL 4.0 as a pediatric population health measure: feasibility, reliability, and validity. Ambul Pediatr 3:329-341

40. Weissberg-Benchell J, Zielinski TE, Rodgers S, Greenley RN, Askenazi D, Goldstein SL, Fredericks EM, McDiarmid S, Williams L, Limbers CA, Tuzinkiewicz K, Lerret S, Alonso EM, Varni JW (2010) Pediatric health-related quality of life:
Feasibility, reliability and validity of the PedsQL transplant module. Am J Transplant 10:1677-1685

41. Reinfjell T, Diseth TH, Veenstra M, Vikan A (2006) Measuring health-related quality of life in young adolescents: reliability and validity in the Norwegian version of the Pediatric Quality of Life Inventory 4.0 (PedsQL) generic core scales. Health Qual Life Outcomes 4:61

42. Goldberg D, Williams P (1988) A user`s guide to the General Health Questionnaire GHQ. NFER-Nelson, Windsor

43. Malt UF (1989) The validity of the General Health Questionnaire in a sample of accidentally injured adults. Acta Psychiatr Scand Suppl 80(355):103-112

44. Burckhardt CS, Woods SL, Schultz AA, Ziebarth DM (1989) Quality of life of adults with chronic illness: a psychometric study. Res Nurs Health 12:347-354

45. Wahl AK, Rustøen T, Hanestad BR, Lerdal A, Moum T (2004) Quality of life in the general Norwegian population, measured by the Quality of Life Scale (QOLS-N). Qual Life Res 13: 1001-1009

46. Kleinbaum D, Kupper L, Muller K (1988) Applied regression analysis and other multivariable methods, 2nd edn. PWS-KENT, Boston

47. Wallander JL, Varni JW (1998) Effects of pediatric chronic physical disorders on child and family adjustment. J Child Psychol Psychiatr 39:29-46

48. Lavigne JV, Faier-Routman J (1992) Psychological adjustment to pediatric physical disorders: a meta-analytic review. J Pediatr Psychol 17:133-157

49. Varni JW, Setoguchi Y (1992) Screening for behavioral and emotional problems in children and adolescents with congenital or acquired limb deficiencies. Am J Dis Child 146:103-137

50. Achenbach TM, McConaughy SH, Howell CT (1987) Child/ adolescent behavioral and emotional problems: implications of cross-informant correlations for situational specificity. Psychol Bull 101:213-232

51. Varni JW, Katz ER, Seid M, Quiggins DJ, Friedman-Bender A, Castro CM, The Pediatric Cancer Quality of Life Inventory (PCQL) (1998) I. Instrument development, descriptive statistics, and cross-informant variance. J Behav Med 21:179-204

52. Wiedebusch S, Konrad M, Foppe H, Reichwald-Klugger E, Schaefer F, Schreiber V, Muthny FA (2010) Health-related quality of life, psychosocial strains, and coping in parents of children with chronic renal failure. Pediatr Nephrol 25:14771485

53. Gjertson DW, Cecka JM (2001) Determinants of long-term survival of pediatric kidney grafts reported to the United Network for Organ Sharing kidney transplant registry. Pediatr Transplant $5: 5-15$

54. Drotar D (1997) Relating parent and family functioning to the psychological adjustment of children with chronic health conditions: What have we learned? What do we need to know? J Pediatr Psychol 22:149-165

55. Hanson CL (2001) Quality of life in families of youths with chronic conditions. Brunner-Routledge, East Sussex

56. Neuhaus TJ, Wartmann M, Weber M, Landolt MA, Laube GF, Kemper MJ (2005) Psychosocial impact of living-related kidney transplantation on donors and partners. Pediatr Nephrol 20:205209

57. Clemens KK, Thiessen-Philbrook H, Parikh CR, Yang RC, Karley ML, Boudville N, Ramesh Prasad GV, Garg AX, Donor Nephrectomy Outcomes Research (DONOR) Network (2006) Psychosocial health of living kidney donors: a systematic review. Am J Transplant 6:2965-2977

58. Goldstein SL (2009) Physical fitness in children with end-stage renal disease. Adv Chron Kidney Dis 16:430-436 
59. Gerson AC, Wentz A, Abraham AG, Mendley SR, Hooper SR, Butler RW, Gipson DS, Lande MB, Shinnar S, Moxey-Mims MM, Warady BA, Furth SL (2010) Health-related quality of life of children with mild to moderate chronic kidney disease. Pediatrics 125:e349-357

60. Pattaragarn A, Warady BA, Sabath RJ (2004) Exercise capacity in pediatric patients with end-stage renal disease. Perit Dial Int $24: 274-280$
61. White K, Kendrick T, Yardley L (2009) Change in self-esteem, self-efficacy and the mood dimensions of depression as potential mediators of the physical activity and depression relationship: Exploring the temporal relation of change. Ment Health Phys Act 2:44-52

62. Bassett DR Jr, Howley ET (2000) Limiting factors for maximum oxygen uptake and determinants of endurance performance. Med Sci Sports Exerc 32:70-84 